First Peoples Child \& Family Review

A Journal on Innovation and Best Practices in Aboriginal Child Welfare Administration,

Research, Policy \& Practice

\title{
Aboriginal Fathers Support Groups: Bridging the Gap between Displacement and Family Balance
}

\section{Candice Manahan and Jessica Ball}

Volume 3, Number 4, 2007

URI: https://id.erudit.org/iderudit/1069373ar

DOI: https://doi.org/10.7202/1069373ar

See table of contents

Publisher(s)

First Nations Child and Family Caring Society of Canada

\section{ISSN}

1708-489X (print)

2293-6610 (digital)

Explore this journal

Cite this article

Manahan, C. \& Ball, J. (2007). Aboriginal Fathers Support Groups: Bridging the Gap between Displacement and Family Balance. First Peoples Child \& Family Review, 3(4), 42-49. https://doi.org/10.7202/1069373ar

\section{Article abstract}

The Aboriginal Fathers Project set out to explore the roles of fathers in British Columbia's Aboriginal families. The project aimed to investigate the ways community programs could support fathers' involvement with their children, and increase their participation in family-centered programs. This article briefly describes the project and outlines a few of the major findings from the research. This article discusses findings from the project which highlight the impact of colonialism and assimilation processes on the roles of Aboriginal fathers. The suggestion to develop father-specific support groups and the use of traditional practices and spirituality in the support groups is discussed.
This document is protected by copyright law. Use of the services of Érudit (including reproduction) is subject to its terms and conditions, which can be viewed online.

https://apropos.erudit.org/en/users/policy-on-use/ 


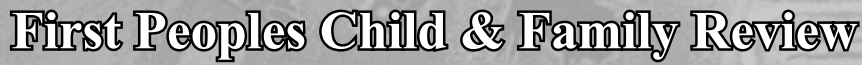

\section{A Journal on Innovation and Best Practices in Aboriginal Child Welfare Administration, Research, Policy \& Practice}

Volume 3, Number 4, 2007, pp. $42-49$

\section{Aboriginal Fathers Support Groups: Bridging the Gap between Displacement and Family Balance*}

\author{
Candice Manahan ${ }^{\mathrm{a}}$ and Jessica Ball ${ }^{\mathrm{b}}$
}

\begin{abstract}
a Candice Manahan is currently completing her Masters degree in Community Health Sciences at the University of Northern British Columbia, in her hometown, Prince George, B.C. Candice is the Field Research Coordinator on the Aboriginal Fathers Project, and she has conducted over 60 conversational interviews with Aboriginal fathers across B.C. Candice's father is of Aboriginal ancestry and her grandfather was a residential school survivor. Candice has experience working with Aboriginal families as a parent support worker in her community.

${ }^{b}$ Jessica Ball, M.P.H., Ph.D., is a professor in the School of Child and Youth Care at the University of Victoria. She is a third generation Canadian of Irish and English ancestry. Over the past decade, she has worked in research and education partnerships with a large number of First Nations and urban Aboriginal community-based programs, focusing especially on early childhood development and fathers' involvement. She was the Principal Investigator of the research reported in this article. Jessica's publications describe applications of local and Indigenous knowledge in research, in community-based service development, and in professional education (visit www.ecdip.org and www.fnpp.org).
\end{abstract}

* This paper draws upon ideas and findings from the first research study of Aboriginal fathers' involvement in Canada, conducted by Jessica Ball and an Indigenous research team, in partnership with five Aboriginal community groups in British Columbia (B.C.). The project was funded by the Social Sciences and Humanities Council of Canada and by the B.C. Ministry for Children and Family Development, through the Human Early Learning Partnership.

Thanks to the Aboriginal fathers and the community-based practitioners who shared their stories for this report. Quotes are from fathers who participated in the research and who gave their written permission to be quoted. Thank you also to Dr. Josee Lavoie at the University of Northern British Columbia for all of her guidance and editorial support.

Questions or correspondence concerning this article may be addressed to:

Candice Manahan robergec@unbc.ca

\begin{abstract}
The Aboriginal Fathers Project set out to explore the roles of fathers in British Columbia's Aboriginal families. The project aimed to investigate the ways community programs could support fathers' involvement with their children, and increase their participation in family-centered programs. This article briefly describes the project and outlines a few of the major findings from the research. This article discusses findings from the project which highlight the impact of colonialism and assimilation processes on the roles of Aboriginal fathers. The suggestion to develop father-specific support groups and the use of traditional practices and spirituality in the support groups is discussed.
\end{abstract}

\section{Introduction}

The well-being of Canada's Aboriginal children depends on the health of their families and their communities (Mussell, Cardiff \& White, 2004). To ensure a positive future for Aboriginal children, one must assess family relationships and roles of family in childhood development. Today, hundreds of community programs have been developed to protect Aboriginal children and promote healthy family relationships (Shangreaux \& Blackstock, 2004). For many years, fathers have been excluded from this assessment, and the benefits of father involvement have been overlooked as a potential resource for Aboriginal children (Ball \& George, 2007). Chief Ed John, the Grand Chief of the First Nations Summit in British Columbia states,
Fathers may very well be the greatest untapped resource in the lives of Aboriginal children. If we can support them to get involved and stay connected with their children, that would be a big protective factor for these youngsters as they grow up (Aboriginal Early Childhood Development Leaders Forum, Vancouver, April 27, 2004 quoted in Ball \& George, 2007).

A family-centered approach to Aboriginal child care has been found to be better suited and more culturally 
appropriate than simply a child-focused approach (Ball, 2005). The family-centered model is preferred in most Aboriginal communities (Ball, 2005). However, many community programs supporting families and child development in British Columbia noted low father participation in their family-centered services.

The Aboriginal Fathers Project set out to explore the roles of fathers in British Columbia's Aboriginal families. The project aimed to investigate the ways community programs could support fathers' involvement with their children, and increase their participation in familycentered programs. This report will very briefly describe the Aboriginal Fathers Project and outline a few of the major findings from the research. A more in-depth report of the Aboriginal Fathers Project and the findings can be found elsewhere (Ball, 2006). This article specifically discusses the findings from the project which highlight the impact of colonialism and assimilation processes on the roles of Aboriginal fathers. The suggestion to develop father-specific support groups, in partnership with family-centered programs, will also be featured. The use of traditional practices and Aboriginal spirituality in fathers' support groups and community programming will then be discussed. Finally, specific recommendations will be made for community program managers who want to support Aboriginal fathers in their parenting journey, and increase father participation in family-centered programs.

\section{Aboriginal Fathers Project- Brief Overview}

The Aboriginal Fathers Project was conducted as part of a larger Canadian exploratory study on fathers' involvement, the Fathers Involvement Research Alliance (www.fira.org). Community early childhood development programs such as the Little Hands of Friendship Aboriginal Head Start Program, Prince George Aboriginal Head Start Program, and the Lil'Wat Nation Pqusnalhcw Child Care Centre were asked to participate in community-university partnerships with the University of Victoria, School of Child and Youth Care, to facilitate the research. The research team then received further requests from individual fathers and other community programs who wanted to participate. The Aboriginal Fathers Project eventually grew to include two more on-reserve community programs, three off-reserve community programs, and several fathers from various urban communities around British Columbia (Ball \& George, 2007).

First Nations and Métis men who self-identified as fathers of at least one child under the age of seven years of age were recruited to participate in the study. The definition of 'father' was left up to self-identification, as the research team quickly learned that many Aboriginal families did not solely depend on the biological father of the child to play the fathering role. The term 'father' came to include biological fathers, step-fathers, partners or former partners of the mothers, grandfathers, and uncles who were the father figures in an Aboriginal child's life. Eighty fathers in various communities across British Columbia participated in a conversational interview, a short survey and a demographic questionnaire. The study included $42(52.5 \%)$ fathers living off-reserve in urban centers, $35(43.8 \%)$ fathers living on-reserve in rural areas, and $3(3.75 \%)$ fathers living off-reserve in rural areas (Ball \& George, 2007).

\section{The Impact of Colonialism and Assimilation Practices on the Aboriginal Father}

Several fathers in the study identified the lasting effects of colonialism and assimilation processes on Aboriginal identity and the role of the father. According to the participants, colonialism and assimilation practices have greatly disrupted the role men play in their families and in their communities. Duran and Duran (1995) argue that the effects of colonization on the role the Aboriginal male are especially damaged because traditionally, the male was the protector of the family and the community. The suppression of the man's ability to protect the family and the fragmentation of the traditional community system has lasting, generational traumatic effects on the Aboriginal father (Duran and Duran, 1995). One participant in the Aboriginal Fathers Project explains,
...the First Nations male, their job title used to be hunting and gathering, used to have to hunt and if you weren't hunting or fishing you were preparing to go hunting, fishing, gathering food, making shelters and doing all those things.... So, that whole thing with the Europeans coming in and wiping it all out.... First it was the residential school and they took away the language, or tried to take the language away. They took the entire role of the male in the First Nations community away so that left a big empty gap for males. They didn't know what to do, where to go, what to say, when to say it or anything. They had to fit in and woman had to play another role in telling the male what to do, but the women kept their jobs. The women looked after the kids, they did all the food preparations and things like that... that stayed. The women fit in a lot easier than the men I think. It wasn't easy for women, but they had certain jobs that they were able to do, whereas the men they had to go off, they had to go and learn how to build certain kind of houses and they had to relearn how to live in society, how to get a wife and what to do as a husband, as a father and as a member of a community (Anonymous, Lil-Wat Nation). 


\section{Aboriginal Fathers Support Groups}

The roles of the Aboriginal father are also disrupted by the trauma caused by colonialism and assimilation processes. The trauma of residential schooling has had lasting effects on many fathers' parenting skills, power to communicate and ability to show affection to their children. As one father from the Aboriginal Fathers Project explains,

\section{Back then, I didn't have any communication skills like normal fathers had. The affection of a loving father-child relationship, like normal fathers have, like kissing your younger children. I only learned that, years later, that was what it takes to love a child. There was nothing like that when I was growing up in a residential school. Because I was in residential school until I was eighteen years old, I really didn't learn anything. No love and no hugs from the priests or the nuns. I just came out cold (Anonymous, Nanaimo).}

This trauma continues today through the generations. Many Aboriginal people who never set foot into a residential school still experience the 'generational cycle of trauma' (See Figure 1). The effects of generational trauma, such as substance abuse or family violence, have left many men without a positive, father figure in their lives while they were growing up. Many men found themselves having children of their own, without a role model to teach them about parenting skills, how to communicate with their child, how to show affection, or how to deal with stressful parenting situations. Similar findings of Aboriginal men left without positive, male role models are documented in a qualitative research study of Aboriginal men's healing in British Columbia (Mussell, 2005). One participant in the Aboriginal Fathers Project describes memories of his own father,

\begin{abstract}
He was abusive. I was only a year old when he left and so I don't know if I ever saw [the violence] or experienced it. He left and then when I was nine, his brother murdered him. He was stabbed in a knife fight. I can remember seeing him and wishing he were more involved. After he died, I had dreams of him and he didn't recognize me. There was a lot of stuff that I had to deal with as I grew up. But, I knew that was not what I wanted for my children. I wanted my children to have a father and to understand the joys and rewards of having both parents in their lives (Earl, Prince George).
\end{abstract}

Many fathers described growing up without a positive father figure, and conveyed the difficulties they had as a child, including feelings of emotional abandonment, family dysfunction, family imbalance and neglect. Participants who did not grow up with a father figure explained that they wanted their children to have

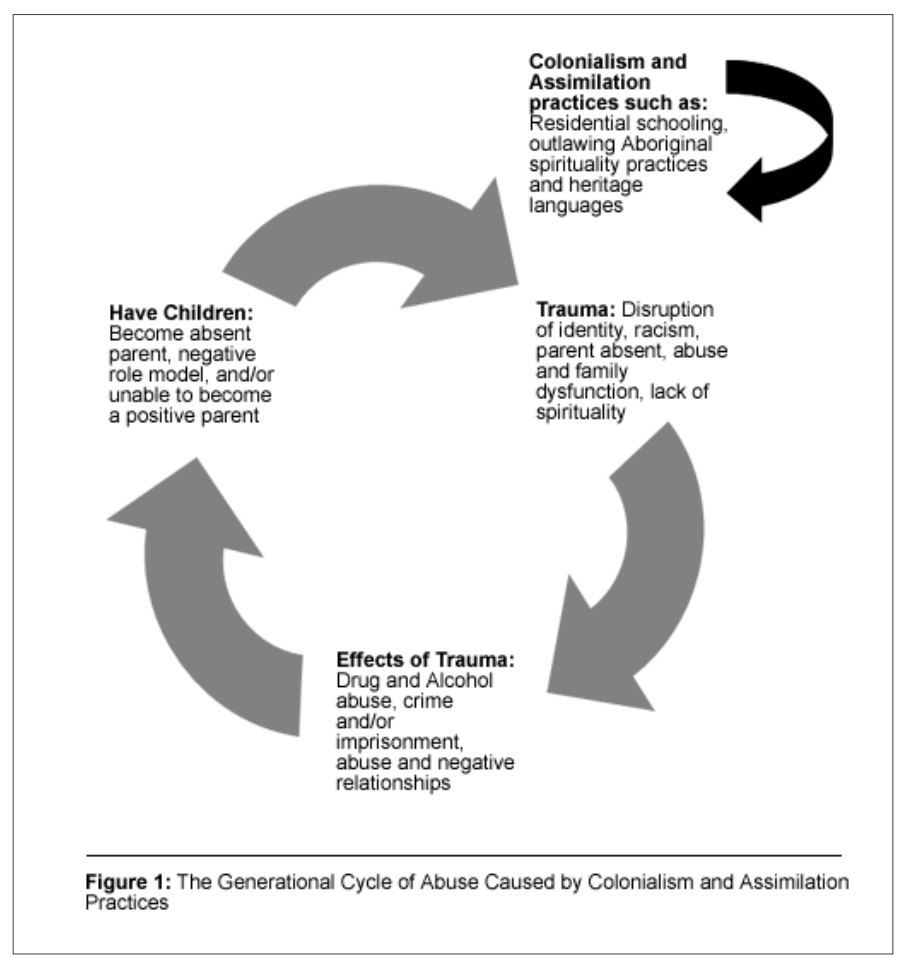

a positive, male role model in their life because they knew how important it was to have that family balance. Several fathers suggested their motivation to become a good parent stemmed from their own childhood without a father. One father explains,

Growing up without a father, without that
disciplinary figure in my life... there was just
certain things that my mother couldn't do. She
raised me well, and she did it all on her own,
but I just know that there were some things that
she just wasn't able to do. I am a bastard child
and I didn't want that for my child.... I did not
want my child to be fatherless and lacking that
discipline and guidance (Brian, Lheidli-Tenneh
First Nation).

Colonialism and assimilation practices, such as - but not limited to - residential schooling, have had a multigenerational effect on the role of the Aboriginal father in both the family and the community. The participants in the study suggest that their positive involvement with their children gives them the opportunity to break that generational cycle of trauma and give their children what they never had growing up.

\section{Aboriginal Fathers' Support Group}

The fathers in the study were asked about how they prepared for becoming a father. Approximately one 
quarter of the men interviewed explained that they had needed to find a positive, male role model in a parenting role. It appears men who want to be positively involved with their children often seek a positive father role model to emulate. For those men who did not have access to a positive father figure or Elder, they often looked to their peers. Nearly one-third of the fathers in the study looked to their community for parenting role models. When the fathers were asked what community programs could do to promote father involvement, several participants suggested the creation of a fathers' support group specifically for Aboriginal men. The fathers suggested that just watching other fathers interact with their children in a positive environment is useful, especially for those who had not grown up with an involved father. Seeing other men, who are similar to themselves interacting with their children in a constructive way, acted as an educational tool and boosted their confidence. In many ways, the role of the support group helped men to redefine what a father is and include other Aboriginal men in that concept. Those participants who had experience as part of a fathers support group reported that their interactions with other fathers acted as both a peer support network and as an affirmation of their fathering role, which enhanced their own beliefs about their ability to be a good father.

The development of a support group specifically for Aboriginal fathers is supported by previous research that suggests the need to develop culture-specific health and family services to support the well-being of Aboriginal people (Kirmayer, Simpson, \& Crago, 2003; Stephens, Porter, Nettleton, \& Willis, 2006). Many of the men in the current study noted that their insecurities about becoming a father stemmed from disruptions in their own cultural identity. The fathers suggested that the role of the Aboriginal father had been damaged; consequently, Aboriginal fathers face added challenges that NonAboriginal fathers may not consider. One father explains,

One thing I notice is a lot of Non-Aboriginal fathers going out with their kids, doing stuff with their kids and it is something I don't really see Native guys doing. [Why do you think that is?] I think it has a lot to do with how they were raised and how they grew up in their own family. It was one thing I noticed was that I didn't do those things before, because I was never taught those things, I never did those things with my family. It is kind of hard (Brian, Prince George).

Participants in the study suggested that an Aboriginal fathers' support group would also give the older or more experienced fathers the opportunity to mentor younger or less experienced Aboriginal fathers. This concept is reinforced by the United Nations Working Group of Indigenous Peoples, which recognizes the importance of empowering younger generations of Indigenous peoples through education and mentorship (Boyer, 2004). This concept is further supported by Canadian research on Indigenous knowledge which suggests that Aboriginal ways of knowing and knowledge must be controlled and driven by Aboriginal people (Hart, 2007). The importance of Aboriginal fathers learning from other fathers is highlighted by one participant from the current project,
I think that father's support is big and being able to see how other fathers handle different situations. Because honestly, there are a lot of fathers out there who weren't raised by a father, or were raised by an abusive father, and don't know how to be a father, like me. My father was not around, so you have to learn right from the beginning, when you have a baby sitting right there in front of you and you have to be a dad. I know that John Howard [Society] has that but it is not specifically for Aboriginal fathers. I think that there is a high degree of cultural shame amongst Aboriginal people and I think that if they could identify with other Aboriginal fathers, share their experiences, share their strengths, then maybe they could step out of that and teach their children how to be proud of who they are (Anonymous, Prince George).

The participants in this study highlight the importance of role models and support networks. Aboriginal fathers' support groups give men the opportunity to share stories, develop social relationships, and watch other men interacting with their children.

\section{Using Traditional Practice and Aboriginal Spirituality in Aboriginal Fathers' Support Groups and Other Community Programming}

Many participants suggested the parenting support groups would further benefit fathers if they included traditional practices and aspects of Aboriginal spirituality. Conceptions of 'traditional practices' and aspects of 'Aboriginal spirituality' differed between individual men and across communities. It is important to recognize the difference between First Nations, Métis and Inuit cultures, just as it is important to recognize the diversity of communities, especially when discussing traditional practices and aspects of Aboriginal spirituality (Adelson, 2005). Due to the cultural diversity of the men in the study, 'traditional practices' and 'Aboriginal spirituality' can not be defined in this paper. The men in the study did refer to the use of traditional drumming, dancing, ceremonies, smudging, sweat lodges, hunting, fishing, berry picking, carving, drum making, healing circles and learning from Elders.

An Aboriginal fathers' support group that promotes the use of traditional practices and spirituality fits the holistic model of wellness. The holistic model of wellness 
focuses on the balance of the physical, emotional, mental, and spiritual aspects of a person within their family and community relationships (Adelson, 2005). Traditional practices have been used to reinforce cultural identity, to nourish family relationships and to promote spiritual wellness (Martin Hill, 2003). Promoting and respecting the use of traditional practices and Aboriginal spirituality in fathers' support groups could create an opportunity for men to regenerate their Aboriginal identity.

Several healing programs have found therapeutic benefits using traditional practices and aspects of Aboriginal spirituality (Archibald, 2006; Waldram, 1997). One father in the Aboriginal Fathers Project explains, "The most important thing I did to prepare to become a father was to heal myself" (Anonymous, Lil-Wat Nation). Hunter, Logan, Goulet, and Barton (2006) suggest the process of healing for Aboriginal men includes a 'cultural path', using traditional practices to find spiritual, emotional, mental and physical balance. Healing circles, sweat lodges, smudging, the use of Elders, and the use of other traditional practices have been used by Kishk Anaquot Health Research to reinforce cultural identity and facilitate healing (Archibald, 2006). Many fathers in the current study reported using traditional practices and Aboriginal spirituality to heal themselves and prepare for fatherhood. When Leroy of Lil-Wat First Nation was asked what prepared him for fatherhood, he explained, "Probably the biggest thing was learning to be a grounded, spiritual person. Learning about how my people have dealt with things in terms of children". Getting in touch with their spirituality and becoming confident with their cultural identity helped these fathers in their parenting journey.

Participants in the Aboriginal Fathers Project noted that they could rekindle their cultural identity, embrace their Aboriginal spirituality and nurture their family relationships through the use of traditional practices. A father in Esketemc First Nation learned more about his traditional practices to further nourish his relationship with his daughter. He explains, "I didn't know any of the songs and now that she likes to Native dance, I kind of have to learn the songs so she has something to dance to!" Many fathers suggested that the use of traditional practices has allowed them to escape the generational cycle of trauma caused by colonialism and assimilation processes, and has been key in their preparation for fatherhood. Aboriginal fathers support programs, as well as other community programs meant to facilitate healing, should promote and respect the use of traditional practices and aspects of Aboriginal spirituality.

\section{Recommendations for Community Programs Who Want to Support Aboriginal Fathers}

The 'mainstream' focus on parent-child relationships in community programs does not address the multidimensional Aboriginal family system or the impact of colonization on this system (Shangreaux \& Blackstock, 2004). The research team quickly learned that many Aboriginal families did not solely depend on the biological father of the child to play the fathering role in a nuclear family setting. The cohesive, multi-generational Aboriginal family is traditionally an arrangement of extended kinships, encompassing responsibilities and roles in raising the children (Shangreaux \& Blackstock, 2004; Turner, 1985). As more Aboriginal people move away from their heritage communities into both rural and urban settings, the nuclear family setting has become increasingly popular (Castellano, 2002). Nonetheless, the concept of having extended family directly involved in raising a child is still a powerful ideal held by Aboriginal people (Castellano, 2002). This belief is very apparent in the findings from this project. However, this concept is not reflective of many child and family programs available to Aboriginal families today. The western ideal of the 'nuclear family' has informed the development of programs today, suggesting that these services may need to be reassessed (Bennett \& Blackstock, 2002; Red Horse et. al., 2000; Shangreaux \& Blackstock, 2004).

Community program development has to be open to the idea that a child may not always belong to the western 'ideal' of a nuclear family. The findings from this study emphasize the need to use a family-centered approach in the development of programs for Aboriginal families, but also emphasize the need to consider the variations that are apparent in families today. Recognizing the roles different family members play in children's lives and how community programs can support them in their parenting roles are imperative to the future of Aboriginal children. Although many community programs have begun to use family-centered models over child-centered service models, recognizing the specific needs of Aboriginal fathers is critical in supporting men in their parenting journey.

\section{Recommendation:}

Recognize the variations across Aboriginal family systems when development community programs. Ensure that family workers know all of the family members and friends who are involved in parenting the child. Ensure that family workers invite all parents 
to activities and follow-up with parents who do not attend.

The study findings suggest that the shift to a familycentered approach is positive, but does not always represent the needs of fathers. Many fathers who tried to participate in family-centered services still felt out of place because they were often one of the only men in the room. Fathers reported feeling uncomfortable as mothers did not include them in the conversations, and childcare providers did not make efforts to include them in activities. One father explains,

\begin{abstract}
When I go to things like that, I just do not feel comfortable. I was going to go to the 'Nobody's Perfect' program, but it is nothing but females in there! I would like to go in there and just start advocating for the fathers. I want to go in there and say, This is a good program, but you have to expand it to include the father's point of view, give them a voice.' And when I try to speak up about it, people just brush it off. They say they have 'enough work to do', and 'we only have a certain amount of time to talk about these issues and maybe we'll just talk about it next time.' Nothing happens (Brian, Lheidli-Tenneh First Nation).
\end{abstract}

According to the participants in this study, the development of Aboriginal father support groups, within or parallel to family-centered services, would encourage fathers' involvement with their children, and could increase fathers' participation in family-based services. The support group would allow fathers to be heard and create the opportunity for men to support one another, while facilitating the move toward a more family-centered approach. Terrace Child Development Center Dad's Group, which is part of the Terrace Child Development family-centered Park Center Services, suggests community programmers need to give men a safe, inviting environment, and a place where they are respected as parents. Further, the fathers need to be given the opportunity to shape the group, and influence the decisions about the activities that will occur in the group. The importance of having full participation in decision making is well documented in the literature, and is central to the creation of culturally appropriate services (Stephens et. al., 2006).

\section{Recommendation:}

Ask one of the fathers in your program or a male family worker to help create a father support group alongside the family-centered services. Create a safe, father-friendly environment with several father resource materials available and a relaxed atmosphere. Ensure that the time is consistent and reliable, regardless of the number of attendees. Allow the fathers to create their own discussion topics, while providing a variety of resources.

Aboriginal fathers' full participation in decision making is especially important to recognize when promoting a holistic approach, with traditional practices and Aboriginal spirituality. Each group will have different needs, traditions and spiritual practices. The cultural diversity of traditional practices must be recognized and appreciated (Martin Hill, 2003). Community programs that use traditional practices and Aboriginal spirituality, stress the importance of developing group-specific healing models (Archibald, 2006; Martin Hill, 2003). Archibald (2006) also suggests that holistic models using traditional practices need to acknowledge the different needs of those Aboriginal people living in urban areas, rural and remote areas, on and off reserve. In the current study, rural community practitioners invited Elders from the community to give advice on their programming and activities. Creating a culturally specific environment can be more difficult in an urban setting, where there is often a culturally-diverse population of men living away from their hereditary lands. In this kind of situation, it is critical that the fathers decide what practices they want to use, without the imposition of a 'pan-Aboriginal' approach. Promoting the use of traditional practices and spirituality, by inviting local Elders and respecting differing perspectives, is the most a programmer can do, the rest needs to be left in the hands of the fathers.

\section{Recommendation:}

Promote spirituality and traditional practices within your community organization, but do not assume everyone is the same. Invite an Elder to visit your community organization or ask the father support group if they would like an Elder to attend their circle.

Finally, Aboriginal fathers' support groups hosted by larger organizations or community programs, have specific challenges that need to be addressed. Research suggests that service providers often do not know enough about First Nations, Métis and Inuit culture, historical experiences, generational trauma, traditional practices and/or holistic approaches to health and well-being (Bartlett, 2004). The holistic perspective of well-being held by Aboriginal people does not always "translate" into the "typical bio-medically based" community programs (Adelson, 2005, p.S46). These findings emphasize the need to educate service providers within the larger organization about the cultural and gender differences they may come across while hosting a support group for Aboriginal men. Respect, consistency, and a safe, non-invasive environment are imperative to the success 


\section{Aboriginal Fathers Support Groups}

of a fathers support group; therefore, educating the staff is essential.

\section{Recommendations:}

Educate all staff, although not all staff may be in direct contact with fathers. Ensure that all staff members are familiar with the importance of fathers involvement, the variation in Aboriginal family systems and cultures, the historical experiences and what that can mean to Aboriginal people today. Expose your staff and program users to resources (such as books, posters or videos) that include and/or promote Aboriginal father involvement.

\section{Conclusion}

This project highlights the need to consider the role Aboriginal fathers play in the well-being of future generations. The research findings suggest the role of Aboriginal fathers within the family, as well as in family-centered activities, have been displaced through colonialism and assimilation processes. According to the men in this study, developing Aboriginal fathers' support groups within, or parallel to, family-centered services would encourage Aboriginal men in their parenting role, as well as increase participation in family-centered services. These findings are not complimentary to the shift away from child-parent centered ideologies; however, the Aboriginal fathers' support group is a step toward increasing father participation in future family-centered services. Further research will be needed to assess the impact of father-specific support programs alongside family-centered services for Aboriginal people.

The use of traditional practices and Aboriginal spirituality in fathers' support groups and community programming is recommended to promote the holistic model of wellness and healing. Further, the use of traditional practices and aspects of spirituality in Aboriginal fathers' support groups gives men the opportunity to regenerate their Aboriginal identity, create a social support network and develop an opportunity for mentorship. The support group could potentially reinforce the men's cultural identity, their role as a father and, in turn, make them feel more comfortable participating in family-centered services. Further research could target the impact of father-specific support programs and traditional practices on the gender balance in the family roles. Aboriginal fathers' support groups, which encompass a holistic approach using traditional practices, could bridge the gap between the displacement of family-centered activities and today's contemporary family-centered program models.

\section{References}

Adelson, N. (2005). The embodiment of inequity. Canadian Journal of Public Health, 96, S45-S61.

Archibald, L. (2006). Decolonization and healing: Indigenous experiences in the United States, New Zealand, Australia and Greenland. Ottawa, ON: Aboriginal Healing Foundation.

Ball, J. (2005). Hook and hub: Coordinating programs to support Indigenous children's early learning and development. Presented at the World Indigenous Peoples' Conference on Education held at the University of Waikato in Hamilton, New Zealand, November 27- December 1, 2005.

Ball, J. (2006). Indigenous Fathers Involvement project description. Retrieved May 27, 2007 from http://www. ecdip.org/fathers/index.htm.

Ball, J., \& George, R. (2007). Policies and practices affecting Aboriginal fathers' involvement with their children. Presentation at Second Tri-Annual Aboriginal Policy research Conference Relationships: Policy, Research, and Results. Report retrieved April 14, 2007, from http://www. cyc.uvic.ca/documents/IF_Ab_Policy_Res_Paper.pdf.

Bartlett, J. G. (2004). Conceptions and dimensions of health and well-being for Métis women in Manitoba. International Journal of Circumpolar Health, 63(Suppl. 2), 107-113.

Bennett, M., \& Blackstock, C.(ed.) (2002). A literature review and annotated bibliography focusing on aspects of Aboriginal child welfare in Canada. Ottawa, ON: First Nations Child and Family Caring Society of Canada. Retrieved May 15, 2007 from http://www.fncfcs.com/docs/ LitReviewEntire.pdf.

Boyer, Y. (2004). The International Right to Health for Indigenous Peoples in Canada. Discussion paper series on Aboriginal health: Legal issues (No. 3). Ottawa, ON: National Aboriginal Health Organization, Native Law Centre, University of Saskatchewan.

Castellano, M. B. (2002). Aboriginal family trends: Extended family, nuclear families and families of the heart. The Vanier Institute of the Family. Retrieved Oct. 1, 2007 from http://www.vifamily.ca/library/cft/aboriginal.html.

Duran, E., \& Duran, B. (1995). Native American Postcolonial Psychology. New York, NY: State University of New York Press.

Hart, M. (2007). Indigenous knowledge and research: The mikiwáhp as a symbol for reclaiming our knowledge and ways of knowing. First People Child and Family Review, $3(1), 83-90$.

Hunter, L.M., Logan, J., Goulet, J., \& Barton, S. (2006). Aboriginal healing: Regaining balance and culture. Journal of Transcultural Nursing, 17(1), 13-22.

Kirmayer, L. J., Simpson, C., \& Cagro, C. (2003). Healing traditions: Culture, community and mental health promotion with Canadian Aboriginal peoples. Australasian Psychiatry, $11, \mathrm{~S} 15-\mathrm{S} 23$. 


\section{First Peoples Child \& Family Review, Volume 3, Number 4, 2007}

Martin Hill, D. (2003). Traditional medicine in contemporary contexts: protecting and respecting Indigenous knowledge and medicine. Ottawa, ONT: National Aboriginal Health Organization.

Mussell, B., Cardiff, K., \& White, J. (2004). The mental health and well-being of Aboriginal children and youth: Guidance for new approaches and services. Chilliwack BC: Sal'i'shan Institute. Report retrieved May 18, 2007 from http://www. crpnm.mb.ca/library/Mental\%20Health\%20of\%20Aborigin al\%20Children.pdf.

Mussell, B. (2005). Warrior-caregivers: Understanding the challenges and healing of First Nations men. Ottawa ON: Aboriginal Healing Foundation.

Red Horse, J., Martinez, C., Day, P.A., Day, D., Poupart, J., \& Scharnberg, D. (2000). Family preservation: Concepts in American Indian communities. Portland, OR: National Indian Child Welfare Association.

Shangreaux, C., \& Blackstock, C.(ed.) (2004). Staying at home: Examining the implications of least disruptive measures in First Nations child and family service agencies. Ottawa, ON: First Nations Child and Family Caring Society of Canada. Retrieved May 20, 2007 from http://www.fncfcs. com/docs/Staying_at_Home.pdf.

Stephens, C., Porter, J., Nettleton, C., \& Willis, R. (2006).

Disappearing, displaced, and undervalued: a call to action for Indigenous health worldwide. Lancet, 367, 2019-2028.

Turner, D. (1985). Canadian ethnology today: Solitudes and shifts. Anthropology Today, 1(4), 13-16.

Waldram, J. (1997). The way of the pipe: Aboriginal spirituality and symbolic healing in Canadian prisons. Broadview Press, Peterborough, ONT. 